\title{
Twice daily versus four times daily treatment with beclomethasone dipropionate in the control of mild childhood asthma
}

\author{
HYWEL WILLIAMS, E R VERRIER JONES, J R SIBERT \\ From the Department of Paediatrics, Llandough Hospital, Penarth, Glamorgan
}

ABSTRACT The effects of controlling childhood asthma of the same daily dose $(400 \mu \mathrm{g})$ of $\stackrel{\circ}{\stackrel{\circ}{\sim}}$ beclomethasone dipropionate, given in two or four equal divided doses from a metered aerosol, 을 were compared in a double blind crossover study. Thirty one children aged 6-14 years completed the study. They had previously been shown to need beclomethasone by showing either symptoms or reduced peak flow when the treatment was withdrawn. They recorded their daytime and night time symptoms on a visual analogue scale and their morning and evening peak expiratory flow (PEF), and recorded their symptomatic use of bronchodilator aerosols. Spirometry was performed at the end of each treatment period. Control of asthma was good on both regimens. There were small differences in both objective and subjective measurements in favour of the four times daily regimen, but none reached statistical significance, apart from patients' assessment of daytime wheeze $(p<0.05)$. In particular, the differences in the results of lung function tests were very small. Compliance was better for morning and evening doses. These results suggest that beclomethasone given as $200 \mu \mathrm{g}$ twice daily is effective in controlling mild childhood asthma. It may be preferable to $100 \mu \mathrm{g}$ four times daily because of better compliance and because it is unnecessary to take medication to school.

Inhaled beclomethasone dipropionate has been used for over 10 years in the treatment of childhood asthma. ${ }^{12}$ During that time many accounts of its usefulness and safety have been published. ${ }^{34}$ The recommended standard dose of $100 \mu \mathrm{g}$ (two puffs from a metered dose inhaler) four times a day has been shown to be effective in controlling symptoms and it can successfully replace oral steroid treatment in a large proportion of steroid dependent patients. This standard dose has been shown not to suppress the pituitary-adrenal axis. ${ }^{56}$ Furthermore, it does not affect linear growth ${ }^{7}$ and has no long term deleterious effect on the bronchial mucosa. ${ }^{8}$

Problems with compliance are more frequent when drugs have to be taken several times a day. ${ }^{910}$ Treatment twice daily is easier to manage than treatment four times daily, especially in children as parental supervision can be more strict and it removes the inconvenience of having to take medication at school.

Address for reprint requests: Dr J R Sibert, Llandough Hospital, Penarth, S Glam CF6 1XX.

Accepled 5 February 1986
Results of a small study of the use of beclomethasone in adults ${ }^{11}$ and experience with another inhaled steroid in children ${ }^{12}$ have suggested that a twice daily regimen could be effective.

This trial was conducted to compare the usefulness in children of twice daily treatment with beclomethasone with that of the previously recommended regimen of four times a day.

\section{Patients and methods}

Thirty nine asthmatic children of up to 14 years of age underwent a period of pretrial assessment. All had been using beclomethasone to control their asthma before the onset of the trial and were able to perform simple lung function tests. Patients who required oral steroids occasionally (more than twice a year) were not included in the study. Informed consent was obtained from the parents and children in each case.

A pretrial period of assessment was considered necessary to prove that the children needed treatment with beclomethasone $100 \mu \mathrm{g}$ four times a day and were therefore suitable for the study. During this three week pretrial period beclomethasone was 
replaced by a placebo aerosol administered in a single blind fashion. Patients who showed a $15 \%$ or more drop in peak expiratory flow (PEF) or an increase in consumption of bronchodilator drugs while their lung function remained steady were entered into the study. Seven patients from the initial group of 39 asthmatic children receiving beclomethasone were excluded as they failed to show either a reduction in PEF or an increase in concurrent antiasthmatic medication. One child was withdrawn during the pretrial assessment because of evident poor compliance.

The remaining 31 children who entered the trial restarted treatment with beclomethasone $100 \mu \mathrm{g}$ four times daily and were given a short reducing course of oral steroids until their respiratory function had improved and stabilised.

Identical looking active and placebo pressurised inhalers were provided to give $200 \mu \mathrm{g}$ twice daily or $100 \mu \mathrm{g}$ four times daily in a double blind fashion. The twice daily regimen was adminstered as two inhalations from each of two active inhalers on waking and on retiring, with two inhalations from a placebo inhaler at noon and teatime. The four times daily regimen was administered by two inhalations from an active inhaler and two inhalations from a placebo in the morning and evening, and two inhalations from an active inhaler at noon and teatime. The trial continued for 12 weeks with crossover taking place at six weeks. All canisters were weighed before and after the trial period to check compliance.

During the trial, records of subjective symptoms of dyspnoea, wheeze, cough, and reduced function were kept on a daily diary card and their severity was indicated on a visual analogue scale. Each of the five symptoms recorded by the patients was allotted a score of 0-20 a day, depending on where a mark was placed along the scale, so that for any one symptom the maximum possible total score for three weeks was 420. Patients also recorded their use of a bronchodilator inhaler during the trial period.

The children (or their parents) measured the PEF three times in the morning after waking and before they took any antiasthmatic medication. They made three further measurements of PEF before the evening doses of beclomethasone. The highest reading on each occasion was recorded. At assessment visits to the clinic $\mathrm{FEV}_{1}$, forced vital capacity (FVC), and slow vital capacity were measured, together with PEF, with the patient's usual flow meter.

Consumption of all antiasthmatic treatment other than beclomethasone was noted and, apart from the use of bronchodilators, was kept constant throughout the period of the trial.

Statistical analysis was restricted to the last three weeks of each treatment period to allow for any carry over effects. The study was carried out in the autumn and winter to avoid the pollen season.

\section{Results}

Twenty five boys and six girls aged 6-14 (mean 9.8) years completed both periods of study. Because of holiday periods and difficulties in travelling to the clinic during the winter months, the duration of the trial periods varied slightly, but all children received at least four weeks of each treatment, and most received six weeks of treatment.

The mean peak flow rates at the initial clinic visit, corrected to percentages of predicted normal values, for the group starting on twice daily treatment and the group starting on treatment four times daily were similar (93\% and $95 \%$ respectively) and showed that asthma was well controlled.

Further analysis of the two subgroups showed no effects of order and thus the data for all of the twice daily and all of the four times daily periods were combined.

\section{SUBJECTIVE MEASUREMENTS}

Mean total symptom scores were similar and low with twice daily and four times daily treatment, and indicated that both regimens provided effective treatment. All of the scores showed a small trend in favour of the four times daily regimen (table 1). This just reached significance in the mean total score for daytime wheeze $(p=0.047$, Wilcoxon matched pair signed ranks test).

\section{OBJECTIVE MEASUREMENTS}

The mean peak flow values in the last three weeks of

Table 1 Scores* (medians and ranges) for the whole group for each symptom during the last three weeks of each beclomethasone regimen ( 31 patients)

\begin{tabular}{llll}
\hline Symptom & Twice daily & Four times daily & $p \dagger$ \\
\hline Cough & $45(0-263)$ & $35(0-177)$ & NS \\
Daytime wheeze & $35(0-236)$ & $21(0-174)$ & 0.047 \\
Night time wheeze & $30(0-207)$ & $16(0-245)$ & NS \\
Breathlessness & $28(0-152)$ & $16(0-163)$ & NS \\
Overall disability & $26(0-181)$ & $14(0-139)$ & NS \\
\hline
\end{tabular}

*Maximum possible score for each symptom $=420$ (20 a day).

+Wilcoxon rank sum test. 
the two periods - that is, with the two treatment regimens-were very similar for both the morning and the evening. Mean morning peak flow was 285 (SD 63) $1 \mathrm{~min}^{-1}$ during twice daily treatment and 288 (63) $1 \mathrm{~min}^{-1}$ during four times daily treatment. Mean evening peak flow was 288 (61) and 291 (64) respectively in the two groups. Little diurnal variation was seen in this group of patients with either treatment.

Only 18 children required a bronchodilator inhaler at any time, 16 while receiving twice daily beclomethasone and 15 during the four times daily regimen. The use of bronchodilator aerosols for most of these children was similar during the two treatment periods. There was slightly greater use of the bronchodilator inhaler during the twice daily treatment but the difference was not significant $(p>0.05$, Wilcoxon matched pair signed ranks test).

Spirometric measurements performed in the clinic at the end of each treatment period showed no significant differences between the periods of twice daily treatment and those of four times daily treatment (table 2).

Table 2 Lung function (means and standard deviations) for the 31 patients at the end of the three weeks' treatment with each beclomethasone regimen

\begin{tabular}{lcc}
\hline Measurement & Twice daily & Four times daily \\
\hline FEV $1(1)$ & $1 \cdot 86(0.52)$ & $1.91(0.53)$ \\
FVC $(1)$ & $2 \cdot 23(0.60)$ & $2 \cdot 24(0.60)$ \\
Relaxed VC $(1)_{\text {PEF }\left(1 \min ^{-1}\right)}^{2 \cdot 10(0.61)}$ & $2 \cdot 17(0.63)$ \\
\hline
\end{tabular}

FVC-forced vital capacity; VC-vital capacity; PEF-peak expiratory flow.

\section{COMPLIANCE}

At the end of the study all of the active inhalers were weighed. Overall compliance with the study medications was good. The use of inhalers in the morning and in the evening was similar for the twice and the four times daily treatment. There was, however, significantly less use of the inhalers for the middle of the day (table 3), which suggests poorer compliance with a four times daily frequency.

\section{Discussion}

The trial has confirmed that beclomethasone at a total dosage of $400 \mu \mathrm{g}$ daily is effective in children (aged 6-14 years) with mild asthma and has shown that this total dose is effective whether given as four doses of $100 \mu \mathrm{g}$ or as two doses of $200 \mu \mathrm{g}$. All the measurements suggest that the four times daily regimen may be marginally more effective than the twice
Table 3 Daily weight (means and standard deviations) of beclomethasone dipropionate inhaled by the 31 patients with the two beclomethasone regimens

\begin{tabular}{|c|c|c|}
\hline & $\begin{array}{l}\text { Twice } \\
\text { daily }\end{array}$ & $\begin{array}{l}\text { Four } \\
\text { times daily }\end{array}$ \\
\hline \multirow{4}{*}{$\begin{array}{l}\text { First active inhaler used } \\
\text { morning and evening } \\
\text { Second active inhaler used } \\
\text { morning and evening } \\
\text { Active inhaler used noon } \\
\text { and teatime } \\
\text { Total daily dose of inhaled } \\
\text { beclomethasone }\end{array}$} & $0.35(0 \cdot 11)$ & $0.33(0 \cdot 14)$ \\
\hline & $0.34(0.12)^{*}$ & - \\
\hline & - & $0 \cdot 28^{*}(0 \cdot 14)$ \\
\hline & $0 \cdot 69$ & 0.60 \\
\hline
\end{tabular}

daily regimen, but none of the differences reached significance except in the subjective assessment of daytime wheeze.

In particular, the differences in peak flow and otherc్ lung function indices are very small. The number of $\stackrel{\circ}{\sim}$ patients in the trial was relatively small and possibly $\vec{\bullet}$ with a much larger sample size clear differences in favour of the four times daily regimen would emerge. Furthermore, the undercompliance with the four times daily regimen may have adversely affected the comparison with the twice daily regimen. It is unlikely, however, that any advantage of the four $\frac{\mathrm{O}}{\mathbb{D}}$ times daily regimen that might be revealed by a more $\varrho$ extensive study would be of clinical importance-and $\overrightarrow{\overrightarrow{0}}$ it would have to be set against the better compliance and greater convenience of the twice daily regimen. Parents are able to supervise morning and evening administration and do not have to worry whether $\overrightarrow{3}$ medication is being taken appropriately, if at all, 웡 during school hours. Many children and their parents and teachers dislike the taking of treatment at school.

\section{References}

1 Godfrey S, Konig P. Beclomethasone aerosol in childhood asthma. Arch Dis Child 1973;48:665-70.

2 Lal S, Harris DM, Bhalla KK, Singhal SN, Butler AG. Comparison of beclomethasone dipropionate aerosol and prednisolone in reversible airways obstruction. Br Med J 1972;iii:314-7.

3 Morrow Brown H, Storey G, Jackson FA. Beclomethasone dipropionate aerosol in longterm $\frac{\vec{D}}{\bar{D}}$ treatment of perennial and seasonal asthma in children and adults: a report of five and a half years' experience in 600 asthmatic patients. $B r J$ Clin Pharmacol 1977;4:359-67S.

4 Brown HM, Bhowmik M, Jackson FA, Thantrey N. Beclomethasone dipropionate aerosols in the treat- 2 ment of asthma in childhood. Practitioner 1980;224: ত 847-51.

5 Bhan GL, Gwynn GM, Morrison Smith J. Growth and 
Twice daily versus four times daily treatment with beclomethasone dipropionate for mild childhood asthma 605

adrenal function of children on prolonged beclomethasone dipropionate treatment. Lancet 1980;i:96.

6 Kershnar H, Klein R, Waldman D, et al. Treatment of chronic childhood asthma with beclomethasone dipropionate aerosols. II-Effect on pituitary-adrenal function after substitution for oral corticosteroids. Pediatrics 1978;62:189-97.

7 Graff-Lonnevig V, Kraepelien SD. Longterm treatment with beclomethasone dipropionate aerosol in asthmatic children with special reference to growth. Allergy 1979;34:57-61.

8 Thiringer G, Eriksson N, Malmberg R, et al. Bronchoscopic biopsies of bronchial mucosa before and after beclomethasone dipropionate therapy. Br J Clin Pharmacol 1977;4:293-4S.

9 Hussar DA. Patient noncompliance. J Am Pharmacol Ass 1975;15(NS):183-90, 197-201.

10 Gatley MS. To be taken as directed. J R Coll Gen Pract 1968;16:39.

11 Munch EP, Taudorf E, Weeke B. Dose frequency in the treatment of asthmatics with inhaled topical steroid. Eur J Respir Dis 1982;63(suppl 122):143-53.

12 Field HV, Jenkinson PMA, Frame MH, Warner JO. Budesonide in childhood asthma. In: Clark TJH, Mygind N, Selroos O, eds. Corticosteroid treatment in allergic airways diseases. Eur J Respir Dis 1982;63 (suppl 122):273-4. 